\title{
Portable Archives: Using Mobile Technology for Archival Education and Outreach in a Campus Community
}

\author{
By April K. Anderson-Zorn
}

\begin{abstract}
Off-campus college and university archives face additional challenges when implementing educational and outreach initiatives. Travel difficulties for patrons, transportation issues for fragile materials, even inclement weather can play significant roles in whether a repository's materials can be used in an educational session in an on-campus classroom. This article explores the challenges an offcampus university archives encounters in incorporating its materials into the campus curriculum. In addition, this article discusses a technology-based solution devised by the university archivist to bring greater access to materials and engage the campus community in interactive archival education.
\end{abstract}

\section{Introduction}

In his article on building archives awareness through advocacy, history professor John J. Grabowski argues that archival repositories must use archival materials as part of an outreach program to build a larger pool of users and potential advocates. As he explains, "heritage becomes tangible only when seen. Hidden in a box, it becomes only another mystery to be associated with the arcane profession of archivist and the dull pursuit of history." ${ }^{1}$ Doing so, Grabowski argues, "will also help create a citizenry more aware of the sources and value of history and heritage." 2 Due to its off-campus location, the Dr. Jo Ann Rayfield Archives at Illinois State University ${ }^{3}$ has also adopted a hands-on approach in its education and outreach. Regularly hosting and participating in classroom sessions and university events, the Rayfield Archives staff choose archival materials that are relevant to classroom outcomes and event themes and that can withstand repeated handling by students and the public. Given that the repository is located three miles off campus, it is imperative that the Rayfield Archives find unique ways to keep the repository and its holdings in the campus's and community's minds.

\section{Archives in the Classroom}

In 1971, Hugh Taylor delivered a paper at the Society of American Archivists annual conference that explored the notion of allowing student access to primary sources. Fifty years later, numerous panels and articles on collaboration and access for students in repositories fill the profession's conferences and journals. However, in 1971, the concept was still new. In his unofficially titled session "Letting Undergraduates Loose in the Archives," Taylor explored the evolution of history education in England and France in the mid-twentieth century. Recalling his days in an English classroom, 
Taylor described textbooks as "source" books meant "to challenge the intellect, to stimulate the imagination, to illustrate the lesson, but not to convert school children into historians." ${ }^{4}$ However, strict use of these works limited students' ability to accurately interpret original documents, as "the visual sense had been largely restricted to the printed page." ${ }^{5}$ In the early 1950s, a records office in the English counties of Lancashire and Essex took part in a traveling exhibit that introduced primary source records to students. Educator G. R. Batho later developed educational kits that provided mimeographed copies of original documents for teachers to use in the classroom. While some in the education community questioned the use of copied primary source materials in the classroom, Taylor argued, "there is evidence that children have a great facility for this task since their minds are not so locked on the printed line as an adult's mind is." ${ }^{\prime 6}$ Ulimately, Taylor predicted that microfilmed and photocopied archival kits would fade, and the use of original archival materials in educational settings would rise. Taylor believed that choosing original materials over a textbook "has everything to do with sensitizing the individual to the incomplete uncertainty of all knowledge" and that "as archivists, we should give a great deal more thought to the implications of manuscripts as communication, as evidence of human transaction as it once was."

In 1989, Carleton College archivist Mark Greene shared Taylor's view. Greene saw his repository's materials as suitable for inclusion in the classroom, though admitting that "college and university archives have special difficulties convincing students and faculty that their primary sources are relevant to the curriculum." ${ }^{8}$ Despite some pitfalls in his outreach attempts, Greene proclaimed "failures happen" and encouraged archivists to "go beyond the traditional" in finding departments, faculty, and nontraditional classroom settings that would not otherwise use the repository's collections. ${ }^{9}$ As was the case for Greene at Carleton College, there are expectations for college and university archives to incorporate their holdings into the campus curriculum. Therefore, for Greene, any use of the repository's materials — traditional or otherwise-would benefit the archives: "Use of any kind begets further use, it would seem, and use of collections is, of course, one of the primary reasons for an archives' existence." ${ }^{10}$

While many articles in the archival literature discuss incorporating primary source materials into the classroom, none address the additional physical challenges off-site repositories face incorporating their materials into the on-campus curriculum. In their 2012 survey of public programming at state university special collections and archives, archivists Kevin S. Fleming and Morna Gerrard found that for those surveyed, threequarters of fund-raising and education events are held at the library. They also noted the "vast majority of the educational events are held in special collections and archives or the library, while 27 percent indicated that they hold events at another facility on campus, and 18 percent are off campus entirely." ${ }^{11}$ In their 2013 survey of 63 special collections at ARL member libraries, librarians Charlotte Priddle and Laura McCann found that 47 facilities (75\%) used off-site storage for their collections. Survey comments "regarding retrieval times for materials and the impact on patron use and satisfaction" commonly cited the negative impact on public service for materials stored in off-site facilities. ${ }^{12}$ These surveys suggest that repositories located on campus often 
use library facilities to hold educational sessions, while off-campus repositories have difficulty incorporating their materials into the classroom and likely focus their attention on other activities.

For off-campus repositories that want to expand their educational outreach, growing social media options are available. For example, Katy Lalonde, Chris Sanagon, and Sean Smith used Twitter to post the daily diary entries of an 1812 Canadian farmer and officer, Ely Playter. Wanting to reach younger audiences, the authors' primary goal was to include the Twitter feed in their educational programming. They asked students in grades 7 through 10 to create comic book pages based on the tweets. Educators could also use the tweets in conjunction with an online educational kit. The authors thought that in reading these tweeted diary entries, "students would find Playter's story interesting and invigorating, thereby helping to promote the importance of the archival record and, by extension, archives themselves." ${ }^{13}$

For some off-site repositories, creating and maintaining a variety of digital collections that can be shared online and through social media is the preferred way of reaching classrooms. However, for some users, the demand for access to physical materials remains. In their article, "Fields of Vision: Toward a New Theory of Visual Literacy for Digitized Archival Photographs," professors Paul Conway and Ricardo Punzalan's investigation into users' contextualization of derivatives of original archival objects offers insights into how users might interact with digital surrogates. Conway and Punzalan's literature review found studies that generally "treat visual images as fixed, controlled objects of retrieval, rather than as evidential sources whose fluidity and variability are themselves factors in the use equation." ${ }^{14}$ The authors believe that the field needs studies that examine how users extract meaning from visual collections and then take that meaning and apply it to context-driven analysis. Using what they call "fields of vision," Conway and Punzalan believe this method to be a way to "illustrate the context and dynamics of access, interpretation, and use of digitized archival photographs" 15 while allowing archivists to learn from how their users work with their collections. However, though digitization is beneficial, Conway and Punzalan caution, "digitization should not be undertaken without profound reflection and critical examination." 16 For the authors, to see an original object only in its derivative form means the loss of the tactile feel of the object. This loss results in "an ephemeral ghost" or "a mere shadow of its former being." ${ }^{17}$

\section{An Off-Campus Archives with On-Campus Demand}

Although adminstriatively the Dr. Jo Ann Rayfield Archives is a department under Milner Library, the campus's main library, it is not physically located on campus but rather three miles north in a shared warehouse space. The only physical access to the location is by private vehicle or walking a three-and-a-half-mile paved trail that runs through the northern part of town. Public transportation does not service this part of town, and a large percentage of the student population comes from the Chicago suburbs and generally does not have a vehicle while on campus. Students, faculty, and 
community members who wish to access the physical holdings of the archives must walk the trail, use a private vehicle, or utilize a ride-share service. Due to its off-campus location, access to the repository can be difficult for many, especially those with financial or mobility concerns.

Since the author's arrival as university archivist at Illinois State University in 2011, she has worked to find ways that make the off-site repository more accessible to the campus and local community. That year, a grant from the State of Illinois allowed the repository to digitize its extensive and often-requested collection of yearbooks and make them available online via the Internet Archive. In subsequent years, the archives was able to add its university catalogs, governance reports, portions of the student newspaper, and 14 books about the university's history. Though researchers regularly request these materials, they represent only a small percentage of the collections the repository holds.

While the repository's online presence has grown, so have the requests for access to its physical collections. Faculty often request repository tours as well as on-campus instruction sessions for their classes on university history, archival literacy, and the archival profession. Many faculty request the use of original photographs, ephemera, selected documents from manuscript collections, and memorabilia such as jackets, sweaters, and Civil War-era swords used by the university's first president. When requested for on-campus sessions, materials are evaluated on a case-by-case basis to determine whether they can be safely transported to the classroom location. On days of inclement weather when materials cannot be protected from the elements during transport, the in-class session is rescheduled. Excluding repository tours and online sessions, the Rayfield Archives facilitates an average of 10 in-class sessions a year using original materials. Prior to 2011, classes at either the repository or on campus were nonexistent. With the increase in demand for services and access to materials at its difficult-to-access off-site location, the university archivist experimented with various technologies to try to bridge the physical gap. One such experiment proved extremely successful, both in the classroom and with the local community. As with all technology, it came with both failures and lessons learned.

\section{The Archives Tablet at Work}

While participating in the 2013 Society of American Archivists Research Forum, the author learned of the Augmented Processing Table, a project by Dr. Ciaran B. Trace and then-PhD student Sarah Buchanan, both of the University of Texas iSchool. Described as "a collaborative research project bridging the fields of Archival Science and Human Computer Interaction," the project used an interactive tabletop that tracked a digital object's movement when interacted with by a human. ${ }^{18}$ After placing digital objects on the tabletop, the researchers asked archivists to arrange the collections. A series of archivists performed the arrangement task as the tabletop collected their data. The goal of the project was to see if technology could help archivists' process collections faster and with greater accuracy. ${ }^{19}$ The author realized that she could utilize 
similar technology at her repository. Instead of tracking archivists' processing movements, the technology would allow users to interact with multiple digital archival objects in a collection at once, as they would in a physical collection in the reading room of a repository. These interactions would give users the impression of working within an archival collection while allowing them the freedom to explore multiple digital objects at once.

The author explored a variety of hardware options. The computer needed to be larger than an average consumer tablet, have software that allows for multiple digital objects to appear on screen for use by multiple users, and be portable for archives staff. Consumer devices such as iPads and Android tablets did not meet the criteria, mostly due to their small screen sizes. The author eventually found a new product by Lenovo called a Horizon 2 tablet. The 27-inch tablet, eventually dubbed "the Archives Tablet," quickly became an integral educational and programming tool for the Rayfield Archives, both in the classroom and at community events.

\section{What Is the Archives Tablet?}

The Archives Tablet serves as a portable, interactive touchscreen device for users to manipulate digital assets that mirror their original collections. These assets are digital copies of small, original collections held at the Rayfield Archives. In an early example, the papers of the university's first president, Charles Edward Hovey, were digitized by the Digitization Center at the Rayfield Archives' parent library, Milner Library, and uploaded to the tablet. Following established digitization standards, archival copies of all digitized files were stored on library servers, and smaller JPEG derivatives were transferred to the tablet. Though only a half linear foot in extent, the collection of almost 200 items including documents, photographs, artwork, and memorabilia took about six months to complete. Approximately 115 documents and photographs were digitized and their digital assets arranged into folders that matched the hierarchy of the original collection. Once folders were uploaded to the tablet, users could access them via the device's proprietary software called Aura and "remove" digital assets to view them. Advantages to viewing the collection on the tablet include being able to enlarge the asset to see penmanship and markings otherwise missed on a small document and pulling multiple assets to view side-by-side. While the Archives Tablet is considered an important part of the Rayfield Archives programming plan, it was originally envisioned as strictly a classroom tool. However, in the early months of the tablet's use in the classroom, it was not an immediate success.

\section{Archives Tablet in the Classroom}

The Rayfield Archives often holds instructional classroom sessions on archives, their use in research, and the archives profession. Requested by faculty, classes can range in size from a few graduate students to up to 50 undergraduates. Due to the off-campus location of the Rayfield Archives, faculty often choose to hold sessions in their campus classrooms or in an instruction classroom in Milner Library. The first few sessions to include the Archives Tablet, led by the university archivist, took place 
in a Milner Library computer lab that holds approximately 40 students. The room, while great for leading lessons on utilizing online archival resources, was not suited for gathering a large group of students around a single table to interact with the device. In addition, the university archivist noticed students who did not want to be "first" to use the tablet. Though generally assumed to be technologically savvy, a few of the students commented to the university archivist that they were afraid of "messing up" in front of their peers. With some enthusiastic cheerleading, the university archivist demonstrated the use of the software and encouraged volunteers to try. Once a few students experimented with the device, they took turns pulling assets from folders, enlarging them on the screen, and quickly answering critical analysis questions about the materials. In subsequent classes, the university archivist arranged for a rotation of exercises giving groups tasks to complete using online archives resources while a smaller group used the Archives Tablet.

However, the Archives Tablet is not suited for some classroom use. A large class number, size and layout of the room (an auditorium, for example), and time constraints have all contributed to a few instances of suboptimal results during a tablet session. In one example, the university archivist brought the tablet to an unfamiliar classroom where she expected approximately 30 students. Instead, the class size was well over 50 and held in a lecture hall. Though she successfully connected the tablet to an overhead screen and demonstrated its use, time and class size prevented student use.

\section{Archives Tablet at Community Events}

While a large class, room size, and time constraints can be obstacles in using the Archives Tablet in an educational setting, using the Archives Tablet at university alumni and community events gave the Rayfield Archives an entirely new and valuable outreach method that has persisted to this day. While educational outreach is an essential function of a university archives, so is community outreach. Connecting with the local community is important, not only to build donor relationships and community trust, and to drive user engagement, but also to be a good community partner and demonstrate the value of having an institutional repository nearby. In her article "Selling the College and University Archives: Current Outreach Perspectives," Tamar G. Chute agrees: "Outreach is a powerful tool: it teaches the university community about the history of the institution as well as about the value of the documents that the institution creates." ${ }^{20}$ Chute interviewed eight college and university archivists for her article and found that they viewed outreach "as being of equal or greater importance to core archival duties such as arrangement and description." ${ }^{11}$ Chute also advocates for exhibits, as they can reach many viewers in multiple constituent groups. Citing institutions that display documents and artifacts in unique ways to draw in patrons, Chute shows that exhibits should be a critical part of any outreach program. However, college and university archives should experiment with various outreach tools and programs to identify what activities best fit their budgets and needs: "College and university archivists should look at other types of archives and, among themselves, find new ideas and examples of public programs they might be able to modify for their own institution." 22 
For the Rayfield Archives, the Archives Tablet has proven to be a successful educational and community outreach tool. The interactive nature of the hardware and the nostalgia the digitized materials elicit in users help to ease initial contact between archives staff, students, and visitors in the classroom and at institutional events. Often, event visitors will recall their own experiences related to a photograph while students may offer their viewpoint on a digitized object. This tool mimics other experimental outreach programs explored by professor Wendy M. Duff and archivist Jessica Haskell. In their research, the authors explore the "Rhizomatic Approach," which is "a nonhierarchical, acentric system with multiple entry and exit points." ${ }^{23} \mathrm{Using}$ examples, the authors show how these efforts allow the public access to archival records and how they can contribute their information about the records. In return, the repository can choose how, if, and in what way it will keep this information. Similarly, the arcHIVE project at the National Archives of Australia allows users to transcribe digitized handwritten documents. As users increase their transcription entries, they can earn points, virtual badges, and other incentives. Duff and Haskell note how social media has changed the way patrons — not just scholars—access and think about archival materials: "This type of engagement in different constructed environments allows multiple pathways for archival users to access records and to participate in the description of archival materials, as well as opening the door and inviting in diverse perspectives instead of a singular meaning." 24

The Archives Tablet has become an indispensable part of Rayfield Archives education and outreach programming. The device elicits conversation and introduces users to the repository, archival materials, and the archival profession. Interacting with the tablet is often less daunting for a student or event visitor who would have otherwise felt intimidated talking directly with the university archivist. Though the repository does not track interaction statistics regarding the tablet's influence on research and donor visits, many visitors to the Rayfield Archives often remark on having learned about the repository through an event that featured the Archives Tablet.

To stay engaged with their older alumni, the university's Alumni Engagement department developed a group known as the Half Century Club. Each year, Alumni Engagement hosts a weekend-long event that welcomes back to campus alumni who graduated 50 years prior. These "inductees" are treated to a black-tie dinner that includes a cocktail hour, presentations and speakers, and retrospectives of the campus from their era. The Rayfield Archives regularly participates in this event, setting up artifact display tables with memorabilia during the cocktail hour and interacting with alumni. At the 2014 Half Century Club induction dinner, the Archives Tablet was added to the artifact display tables to showcase photographs from the collections. 


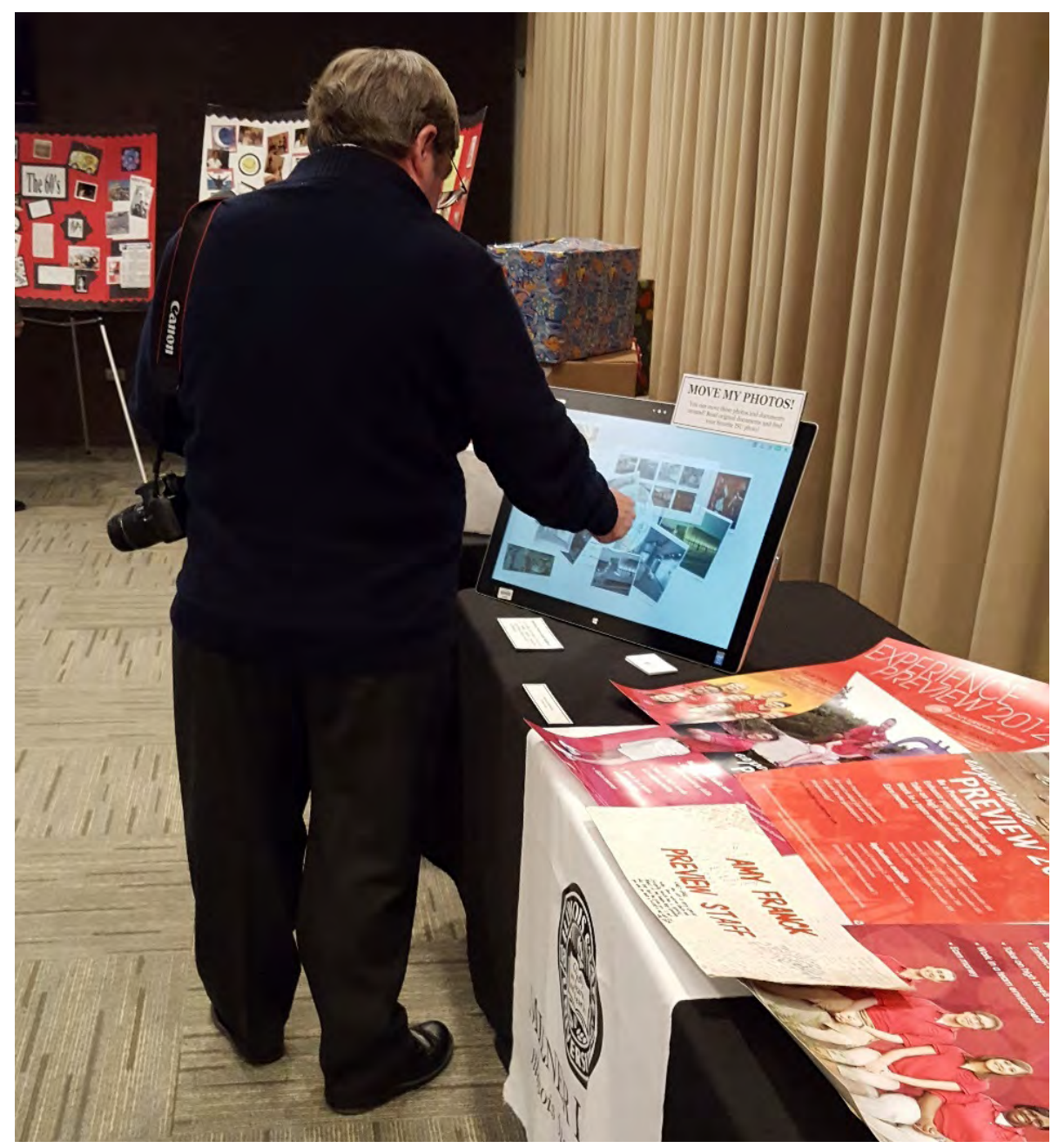

Figure 1: A patron uses the Archives Tablet at a community event sponsored by Illinois State University on April 23, 2016.

Alumni could choose from a variety of subject-based folders on the tablet, including homecoming, sports, graduation, classroom scenes, and residence halls, and browse a selection of digitized photographs highlighting the class of 1964. Though the university archivist was on hand to guide alumni and their families in using the tablet, everyone readily accessed the device with little assistance. Those who spent time with the tablet engaged with the university archivist, offering stories about the photographs and, in some cases, offering to donate memorabilia they had saved from their time on campus. The university archivist regularly takes the Archives Tablet to other alumni-focused events including speaking engagements, celebrations, and universitysponsored events such as Homecoming and Founders Day. 


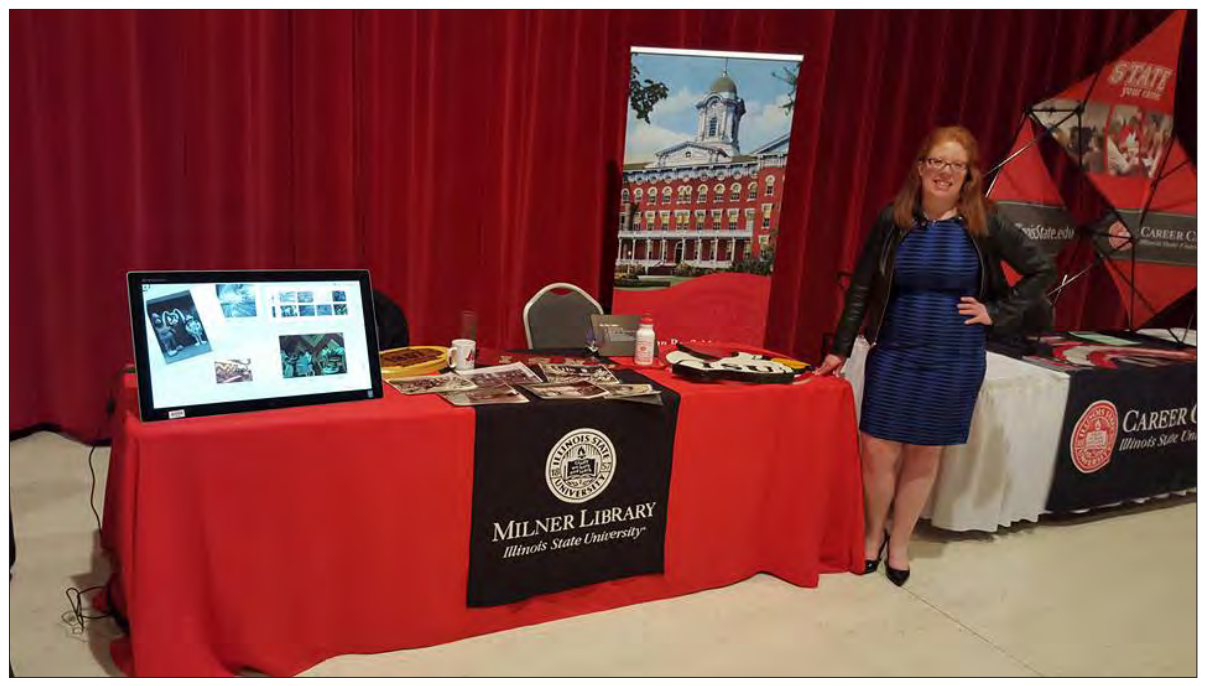

Figure 2: The Archives Tablet in use during the annual Illinois State University Founders Day event on February 18, 2016.

The Archives Tablet has also appeared at specialty events including a fund-raising gala held in 2016 at the Crystal Gardens located at Chicago's Navy Pier. Three hundred alumni browsed themed areas, including three that highlighted the university's war and athletics history using materials from the Rayfield Archives.

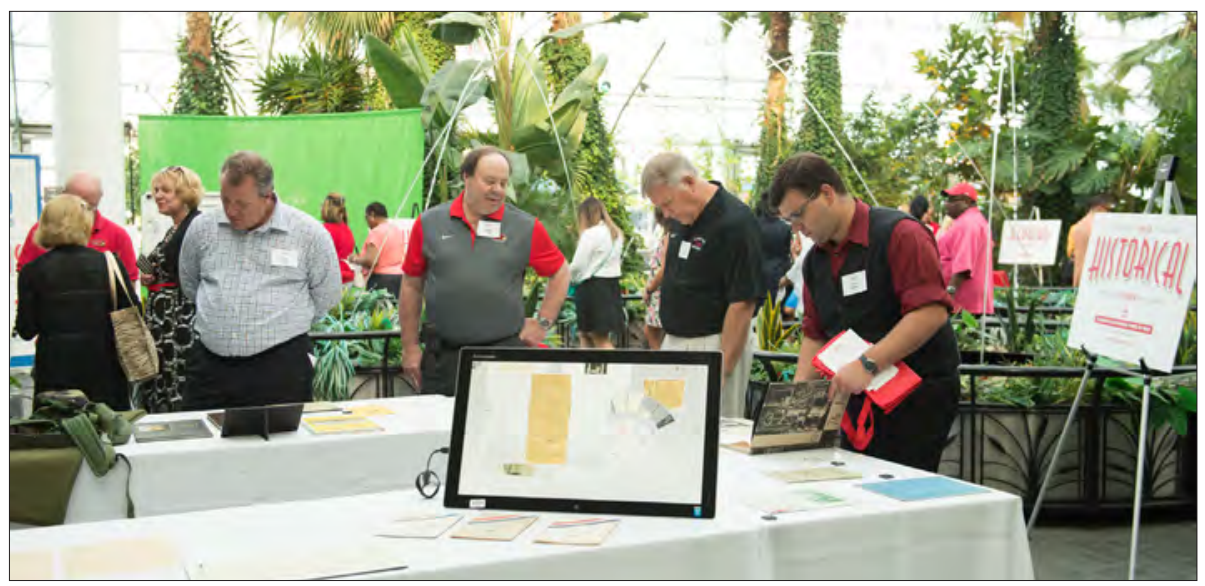

Figure 3: The Archives Tablet in use during an Illinois State University alumni event held at the Crystal Gardens, Chicago, Illinois, on June 22, 2016.

The archives used the Archives Tablet to feature dozens of digitized letters and photographs of university students and alumni who served in World War I. Users could 
browse selected records and learn about the many men and women who served in numerous roles both at home and overseas during the Great War. With only four archives staff on hand at the gala, the Archives Tablet served to keep users engaged with archives materials until a staff member could greet them. The war-themed display tables also featured artifacts used by alumni and faculty in various conflicts from the Civil War to the Iraq War.

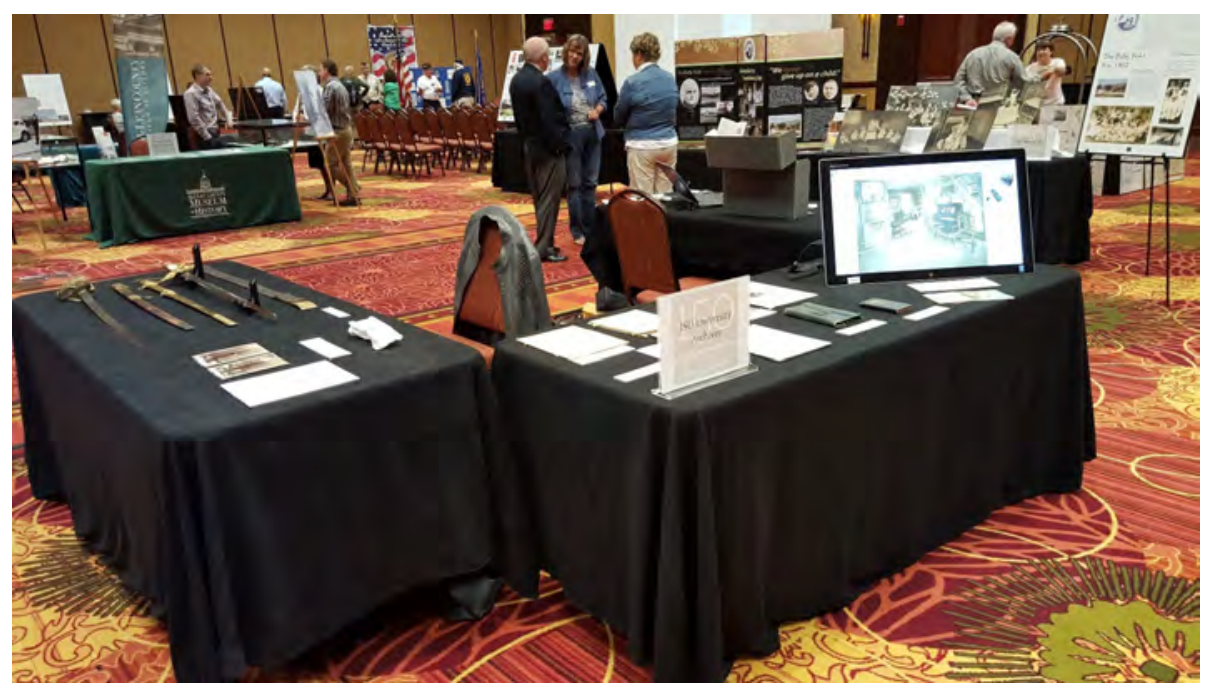

Figure 4: The Archives Tablet in use during the Town of Normal, Illinois, 150th anniversary celebration on September 13, 2015.

\section{Archives Tablet 2.0 Lessons Learned}

For three years, the Archives Tablet served an important role in Rayfield Archives education and outreach initiatives. However, in 2017 the Archives Tablet suffered a software failure during a university event. Lenovo had abruptly stopped updates for Aura, the proprietary software on its Horizon tablets, thus forcing the device's digital object software to become inactive. To salvage the hardware, Milner Library's technology services department, Library Information and Technology Services (LITS), sourced another digital object software solution, Intuiface. The new software simulated many of the attributes of the tablet's proprietary software and provided users other interactive experiences with digital objects. ${ }^{25}$ Given that Lenovo no longer supported the Archives Tablet, LITS sourced and purchased an all-in-one desktop, the Dell OptiPlex 7760, which has many of the same hardware and software features as the original device, but also has drawbacks. While the 16-pound Lenovo could be carried in a sturdy bag, the 20-pound Dell must travel in a 40-pound hard-sided case. Setup requires more time, and storage of the case during an event can be cumbersome. Finally, while the original device could run on battery power at an outdoor event, the new Archives Tablet must always be tethered to an electrical outlet. 
While the new device accomplishes the same tasks and goals set forth for the original tablet, it lacks ease of transport and setup, and it cannot operate in environments that lack power. Staff has quickly adapted to the Intuiface software to create interactive displays for the new Archives Tablet, but they must rely on the software's developers to continue updating the product. LITS also continues to support the Archives Tablet by remotely pushing regular updates to the device's operating system. Though the new Archives Tablet has presented challenges in its use, it has already provided the Rayfield Archives valuable feedback that will be used for the next iteration of the Archives Tablet.

\section{Impact of COVID-19}

The global COVID-19 pandemic has changed many aspects of daily life, including how libraries and archival repositories meet patron needs. Once bustling reading rooms are empty, materials must be quarantined between use, and in-person public events have been canceled. As this article was first written before the start of the pandemic, the use of the Archives Tablet was then generally considered safe. However, as understanding about the virus's transmission has evolved and many around the globe have quarantined in their homes, new questions have arisen about safe use of the Archives Tablet at public events. According to the Centers for Disease Control and Prevention (CDC), the virus is spread via respiratory droplets from person to person and "transmission of novel coronavirus to persons from surfaces contaminated with the virus has not been documented." ${ }^{26}$ While more testing needs to be completed to understand how COVID-19 is transmitted, the CDC believes transmission is far less likely to occur between surfaces and human interaction than it is between humans. However, cleaning and disinfecting of surfaces is still recommended, especially in high-traffic areas. For electronics, the CDC recommends following manufacturer cleaning instructions. For items without manufacturer guidance, it encourages users to "consider the use of alcohol-based wipes or sprays containing at least $70 \%$ alcohol to disinfect touch screens," or to use wipeable covers. $^{27}$

The Rayfield Archives is currently not holding or attending any public events, and outreach and in-classroom sessions will resume once the university and State of Illinois have lifted mandates for social distancing. In the meantime, archives staff are considering new procedures to follow when using the Archives Tablet in public venues. These potential procedures include identifying and using wipeable and/or disposable covers for the touchscreen; wiping down the screen with LITS-approved wipes/cleaner after each patron use; providing hand sanitizer for Archives Tablet users; and disinfecting the Archives Tablet immediately after each event. With these new Archives Tablet cleaning procedures in place, the Rayfield Archives hopes to keep its staff and patrons safe and healthy at all future public events.

\section{Conclusion}

Education and outreach are critical components in any college and university archives 
program. These repositories should find ways to include their materials in classroom settings and are encouraged to find nontraditional disciplines with which to partner. Campus and community events are excellent ways to connect potential users with materials and should be integral to any repository's outreach plan. While digitization and online access might be enticing ways to draw users, some archivists question whether presenting a digital derivative rather than the original document is doing a disservice to the repository and its collections. However, other archivists feel that by presenting digital objects in nontraditional settings that allow the public to contextualize them in their own way brings about a stronger connection been the repository and its users. For the Rayfield Archives, being an off-campus repository with on-campus demand requires unique and experimental ways to bring archival materials to users. With the Archives Tablet, the archives found a mobile technology solution to a physical, location-based problem. Though the technology has had its flaws, the concept has proven popular for its user base.

Ultimately, this tool works for the Rayfield Archives. The Archives Tablet draws in students, community members, and potential donors and introduces to them an opportunity to connect with archives staff. However, the repository is at the mercy of proprietary software companies that choose when and how to service their products. As demonstrated by the interactions in the classroom and at community events, the author feels that the Archives Tablet is an integral part of the repository's outreach plan. Continued use and experimentation with this concept will highlight new ways to enhance the hardware and software of the Archives Tablet and continue to engage its user base.

\section{ABOUT THE AUTHOR}

April K. Anderson-Zorn is the university archivist for Illinois State University. Anderson-Zorn holds a master's degree in history from the University of Central Florida and an MLIS from Florida State University. She is a certified archivist through the Academy of Certified Archivists and holds a Digital Archives Specialist Certificate through the Society of American Archivists. Anderson-Zorn is active in the Society of American Archivists and the Midwest Archives Conference, presenting on topics and authoring articles related to university archives outreach, projects, and tools.

\section{NOTES}

1. John J. Grabowski, "Keepers, Users, and Funders: Building an Awareness of Archival Value," American Archivist 55, no. 3 (1992): 471, https://doi.org/10.17723/aarc.55.3.r9gmpj0rj8530811.

2. Ibid., 464.

3. The Dr. Jo Ann Rayfield Archives is the official repository for Illinois State University. The repository is named for its former repository head and Illinois State University history professor Dr. Jo Ann Rayfield.

4. Hugh A. Taylor, "Clio in the Raw: Archival Materials and the Teaching of History," American Archivist 35, nos. 3-4 (1972): 318, https://doi.org/10.17723/aarc.35.3-4.x2626ht453850482. 
5. Ibid., 318 .

6. Ibid., 323.

7. Ibid., 329-30.

8. Mark A. Greene, "Using College and University Archives as Instructional Materials: A Case Study and an Exhortation," The Midwestern Archivist 14, no. 1 (1989): 31, https:/www.jstor.org/ stable/41101737.

9. Ibid., 34-35.

10. Ibid., 36.

11. Kevin S. Fleming and Morna Gerrard, "Engaging Communities: Public Programming in State Universities' Special Collections and Archives," Archival Issues 36, no. 1 (2014): 16, http://digital .library.wisc.edu/1793/73927.

12. Charlotte Priddle and Laura McCann, "Off-Site Storage and Special Collections: A Study in Use and Impact in ARL Libraries in the United States," College and Research Libraries 76, no. 5 (2015): 659, https://doi.org/10.5860/crl.76.5.652.

13. Katy Lalonde, Chris Sanagan, and Sean Smith, "The War of 1812 in 140 Characters or Less: 'SuperCool or Super Un-tweet Worthy?,' American Archivist 77, no. 2 (2014): 561, https://doi .org/10.17723/aarc.77.2.7016748180782733.

14. Paul Conway and Ricardo Punzalan, "Fields of Vision: Toward a New Theory of Visual Literacy for Digitized Archival Photographs," Archivaria 71 (Spring 2011): 65, https://archivaria.ca/index .php/archivaria/article/view/13331.

15. Ibid., 65 .

16. Ibid., 69 .

17. Ibid., 70.

18. Ciaran B. Trace and Sarah Buchanan, "Enhancing Evidentiary Work through the Lens of Human Centered Computing," presentation at the Society of American Archivists Research Forum, August 13, 2013, https://pdfs.semanticscholar.org/cd36/3294e7fe03bb555d979bcb1851726d287d01.pdf.

19. Ibid.

20. Tamar G. Chute, "Selling the College and University Archives: Current Outreach Perspectives," Archival Issues 25, nos. 1-2, (2000): 34, http://hdl.handle.net/1811/49771.

21. Ibid., 37.

22. Ibid., 47.

23. Wendy M. Duff and Jessica Haskell, "New Uses for Old Records: A Rhizomatic Approach to Archival Access," American Archivist 78, no. 1 (2015): 48, https://doi.org/10.17723/0360-9081.78.1.38.

24. Ibid., 44.

25. Intuiface, Homepage, https://www.intuiface.com.

26. Centers for Disease Control and Prevention, "Cleaning and Disinfection for Households: Interim Recommendations for U.S. Households with Suspected or Confirmed Coronavirus Disease 2019 (COVID-19)," https://www.cdc.gov/coronavirus/2019-ncov/prevent-getting-sick/cleaningdisinfection.html.

27. Ibid. 